Michael J. Morris

\title{
Warding Off Evil
}

\section{Apotropaic Tradition in the Dead Sea Scrolls and Synoptic Gospels}

[Das Böse abwehren. Apotropäische Überlieferungen in den Schriftrollen vom Toten Meer und den synoptischen Evangelien.]

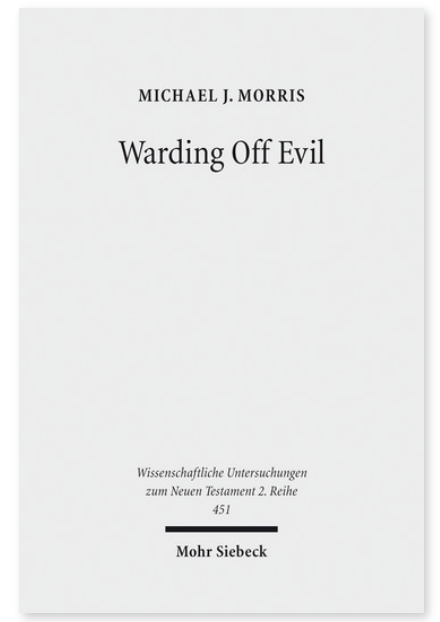

2017. XV, 296 Seiten. WUNT II 451

ISBN 978-3-16-155585-5

DOI 10.1628/978-3-16-155585-5

eBook PDF 104,00€

ISBN 978-3-16-155263-2

fadengeheftete Broschur 104,00€
Veröffentlicht auf Englisch.

Michael J. Morris untersucht in dieser Studie Aspekte der Dämonologie in den synoptischen Evangelien; insbesondere die Reaktion der Menschen auf das dämonische Böse. Die frühchristliche Dämonologie kann freilich besser vor dem Hintergrund früher jüdischer Überlieferungen verstanden werden. In den Schriftrollen vom Toten Meer gibt es beispielsweise zwei wesentliche Methoden anhand derer Schutz gegen die Dämonen ersucht wird. Die erste anti-dämonische Methode ist »Exorzismus«; die zweite zeichnet sich durch ihre präventive Charakteristik aus und wird normalerweise als »apotropäische Handlung« bezeichnet. Obwohl es bereits viele Forschungsbeiträge zum Thema Exorzismus in den Evangelien gibt, wurde den apotropäischen Merkmalen in den Evangeliumstexten bisher wenig Aufmerksamkeit geschenkt. Deshalb bietet Michael J. Morris eine zeitgemäße Untersuchung der apotropäischen Überlieferungen im frühen Judentum und deren Bedeutung für dämonologische Stellen in den synoptischen Evangelien.

Michael J. Morris Born 1983; BA University of Mary, MA Augustine Institute, and PhD University of Dublin, Trinity College; currently faculty at the Catholic Biblical School, a division of the St. John Vianney Theological Seminary in Denver, CO.

Jetzt bestellen:

https://mohrsiebeck.com/buch/warding-off-evil-9783161555855?no_cache=1

order@mohrsiebeck.com

Telefon: +49 (0)7071-923-17

Telefax: $+49(0) 7071-51104$ 